\title{
A study of peripheral leucocyte migration in agarose medium in inflammatory bowel disease
}

\author{
WITOLD BARTNIK ${ }^{1}$, E. T. SWARBRICK ${ }^{2}$, AND CHRISTOPHER WILLIAMS \\ From St Mark's Hospital, London
}

SUMMARY The migration of peripheral leucocytes from patients with inflammatory bowel disease was investigated using an agarose plate technique and three antigenic materials: (1) the enterobacterial common antigen of Kunin; (2) extract from germ-free rat faeces; and (3) Kveim suspension from a sarcoid spleen K19. Inhibition of migration was obtained only with Kunin antigen. It was present in 11 out of 20 patients with ulcerative colitis and in four out of 20 patients with Crohn's disease but in only one out of 33 control subjects. These findings suggest the possibility that a state of cellular immunity to enterobacterial common antigen may exist in inflammatory bowel disease. Lack of cellular reactivity to extract from germ-free faeces and Kveim suspension is in contrast with the results obtained by others by means of the capillary tube method and requires further investigation.

Although the aetiology of ulcerative colitis and Crohn's disease remains unknown, there is evidence to suggest that cell-mediated immune mechanisms may be involved in their pathogenesis (Kraft and Kirsner, 1971). Certain bacterial antigens may play an important role in this process, particularly those crossreacting with components of the intestinal mucosa (Shorter, Huizenga, Spencer, Aas, and Guy, 1971). So far many authors have studied serological responses to Escherichia coli 014 (Thayer, Brown, Sangree, Katz, and Hersh, 1969; Lagercrantz, Perlmann, and Hammarström, 1971), which has been found to possess shared antigenic determinants with colonic antigen(s) extractable from germ-free gastrointestinal mucins (Perlmann, Hammarström, Lagercrantz, and Gustafsson, 1965). However, the common antigen of Kunin, present in most strains of Enterobacteriaceae (Kunin, 1963), is equally interesting both as a component of $E$. coli 014 and as related to antigens deriving from germfree rat colon or faeces (Perlmann et al, 1965; Lagercrantz, Hammarström, Perlmann, and Gustafsson, 1968).

In the present study we have used Kunin antigen to induce inhibition of the migration of peripheral leucocytes taken from patients with inflammatory

Present address: Department of Gastroenterology and Metabolism, Medical Centre of Postgraduate Education, Goszczynskiego 1, 02-616 Warsaw, Poland

'Reprints from E.T.S., St Mark's Hospital, City Road, London, EC1V 2PS.

Received for publication 31 January 1974. bowel disease. It was also our aim to find a simple immunological test to distinguish ulcerative colitis from Crohn's disease. We have therefore employed an agarose plate technique as described by Clausen (1971) and introduced two other antigenic materials which in previous studies performed by means of the capillary tube method seemed to differentiate the conditions. These materials were an extract from germ-free rat faeces (Bendixen, 1971) and Kveim suspension prepared from sarcoid spleen K19 (Willoughby and Mitchell, 1971).

\section{Material}

Four groups of subjects were studied.

\section{ULCERATIVE COLITIS}

Twenty patients with ulcerative colitis (13 females and seven males) aged from 21 to 72 years, had had the disease for three weeks to 15 years. In five of these patients the disease was confined to the distal part of the large bowel, in 11 there was substantial, and in four total involvement. Eight patients in this group were receiving systemic steroids at the time of testing.

\section{CROHN'S DISEASE}

Twenty patients with Crohn's disease (14 females and six males), aged from 18 to 67 years, had a history varying from one year to 23 years. There were four cases with small bowel disease, six with colonic disease only and 10 cases with ileo-colonic involve- 
ment. Thirteen of these patients were receiving systemic steroids at the time of study.

\section{HOSPITAL PATIENTS WITH OTHER DISEASE OF THE LARGE BOWEL}

Fifteen hospital patients (six females and nine males), aged from 25 to 72 years, had been admitted with a variety of other diseases of the large bowel including carcinoma of the rectum (four), haemorrhoids (four), diverticular disease (two), villous papilloma (one), prolapse of the rectum (one), cathartic colon (one), lymphosarcoma of the colon (one), and constipation (one).

\section{HEALTHY VOLUNTEERS}

Eighteen healthy persons from among the hospital laboratory staff, aged from 20 to 38 years and comprising eight males and 10 females, volunteered.

The diagnoses of ulcerative colitis and Crohn's disease were based upon the usual clinical, radiological, and histopathological criteria. Patients in whom the diagnosis was doubtful were excluded from this study.

No patient was receiving azathioprine at the time of the tests.

\section{Methods}

PREPARATION OF LEUCOCYTE SUSPENSIONS Thirty $\mathrm{ml}$ of venous blood was mixed immediately with $5 \mathrm{ml} 6 \%$ dextran 110 in normal saline containing 250 units of preservative-free heparin and allowed to sediment for one hour at $37^{\circ} \mathrm{C}$. The leucocyte-rich plasma was removed, centrifuged at $800 \mathrm{rpm}$ for five minutes, and the cell pellet was washed three times in tissue culture medium 199 (TC medium 199, Difco Laboratories, Detroit, Michigan, USA). The cells were then counted and resuspended in TC medium 199 containing $10 \%$ horse serum, the final volume being adjusted to contain $400 \times 10^{6}$ leucocytes $/ \mathrm{ml}$. The average differential count was $25 \%$ mononuclear and $75 \%$ polymorphnuclear leucocytes. Red cell contamination of the leucocyte suspension was usually less than $1: 1$.

\section{MATERIALS USED AS ANTIGENS}

\section{Kunin antigen}

The enterobacterial common antigen of Kunin was a gift from Dr S. Kaluzewski of the State Institute of Hygiene, Warsaw. It was prepared from Salmonella typhi $901-0$ by ethanol extraction (Suzuki, Gorzynski, and Neter, 1964) and contained $30 \%$ protein (Lowry assay). The antigenic specificity and purity of the preparation were proved serologically. The antigen was active in passive haemagglutination and haemagglutination inhibition tests with $E$. coli 014 antiserum and did not react with serum containing antibodies against 0 antigens of Salmonella typhi.

\section{Germ-free rat faeces}

An extract of germ-free rat faeces was prepared from material supplied by Professor P. Perlmann of the Wenner-Gren Institute, Stockholm, by phenolwater extraction (Hammarström, Lagercrantz, Perlmann, and Gustafsson, 1965) and contained 6\% protein (Lowry assay). Its antigenic specificity was not assessed.

\section{Kveim suspension}

Lot 2 of a preservative-free Chase-Siltzbach type III Kveim suspension derived from sarcoid spleen K19 was kindly supplied by Dr C. M. Patricia Bradstreet, Standards Laboratory for Serological Reagents, Colindale.

\section{LEUCOCYTE MIGRATION USING AN AGAROSE} PLATE TECHNIQUE

The method described by Clausen (1971) was followed with small modifications. Freshly prepared $2 \%$ agarose solution (Indubiose A37, L'industrie Biologique Francais SA, Genneviliers, France) was mixed at $47^{\circ}$ with horse serum (horse serum no. 2, Wellcome Reagents Ltd, Beckenham, England), sterilized distilled water, penicillin, streptomycin, and $10 \times$ concentrated tissue culture medium 199 (TC medium 199, Difco Laboratories, Detroit, Michigan, USA), so that the final solution contained $1 \%$ agarose, $10 \%$ horse serum, 50 units $/ \mathrm{ml}$ of penicillin, and $50 \mu \mathrm{g} / \mathrm{ml}$ of streptomycin in a singlestrength TC medium 199 . A $4 \cdot 4 \%$ solution of sodium bicarbonate was added to maintain the $\mathrm{pH}$ of the agarose medium after incubation in $2.5 \% \mathrm{CO}_{2}$ in air saturated with water vapour between $7 \cdot 2$ and $7 \cdot 4$.

Fifteen $\mathrm{ml}$ of agarose medium was poured onto disposable, non-cytotoxic, plastic petri dishes $9 \mathrm{~cm}$ in diameter (Nunclon, A/S Nunc, Roskilde, Denmark). After the gel had formed, 12 to 15 holes $2 \cdot 3$ $\mathrm{mm}$ in diameter were cut in each agarose plate using a stainless steel punch.

Antigens, or phosphate buffer in saline as a control, were added to the same volumes of the cell suspension; the final concentration of cells was then $200 \times 10^{6} / \mathrm{ml}$. While Kveim suspension was applied without any preparation, the Kunin antigen and the extract from germ-free rat faeces were used in several different dilutions. All subjects were tested with Kunin antigen at the concentration of $25 \mu \mathrm{g}$ protein $/ \mathrm{ml}$ which in a preliminary study seemed to avoid non-specific inhibition of migration of leucocytes from normal subjects. Additionally, in 


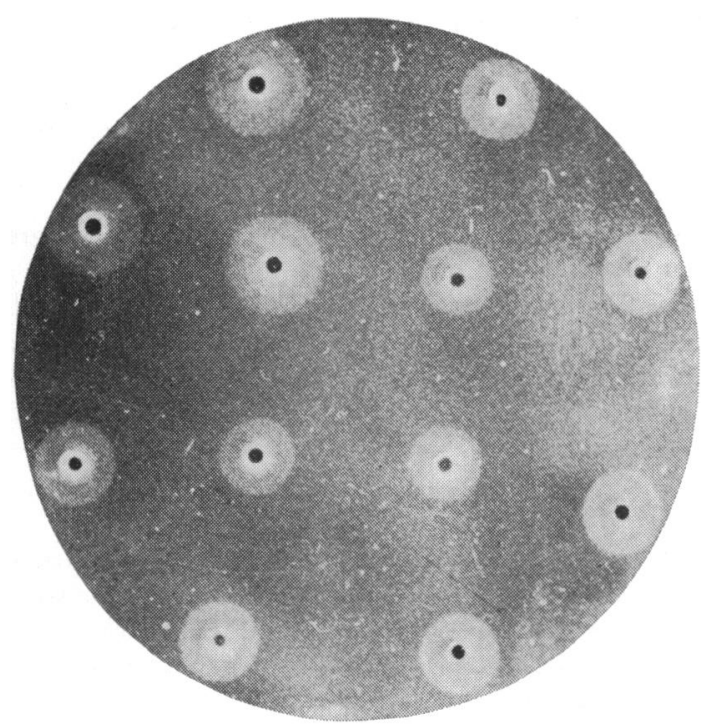

Fig 1 Petri dish with agarose medium after 24 hours of incubation. Areas of migration are seen around the holes. Leucocytes were taken from a patient with ulcerative colitis. The three holes in the left upper quadrant of the plate were filled with leucocytes and phosphate buffer (control), the remaining holes with leucocytes mixed with Kunin antigen in several different dilutions.

some cases this antigen was used in a very wide range of concentrations ( 500 to $0.25 \mu \mathrm{g}$ protein $/ \mathrm{ml}$ ) in order to study migration inhibition quantitatively. Extracts from germ-free rat faeces were applied in concentrations ranging from 125 to $500 \mu \mathrm{g}$ protein/ $\mathrm{ml}$.

The leucocyte-antigen mixtures were preincubated at $37^{\circ} \mathrm{C}$ for $30 \mathrm{~min}$ and pipetted in $8 \mu \mathrm{l}$ aliquots containing about $1.6 \times 10^{6}$ leucocytes into each of the holes cut in the agarose plates. All tests were performed in triplicate, sometimes on one plate and sometimes on more than one plate.

The plates were then incubated for 24 hours at $37^{\circ} \mathrm{C}$ in $2.5 \% \mathrm{CO}_{2}$ in air saturated with water vapour. During this period leucocytes migrated from the holes to give a circular halo of cells beneath the agarose gel (fig 1). Red cells did not spread outside the holes. Areas of migration were mapped after magnification by projection microscopy and measured by planimetry. Within each set of replicate tests the migration areas did not vary by more than $\pm 5 \%$.

The results were expressed as the 'migration index' (MI) which is the ratio between the average area of migration developed with and without antigen.

In 20 experiments the observer was unaware of the diagnosis of the subjects studied so that part of the tests was read blind.

\section{Results}

The results obtained with Kunin antigen using a concentration of $25 \mu \mathrm{g}$ protein $/ \mathrm{ml}$ are shown in the scattergram (fig 2).

The normal range of the migration index (mean $\pm 2 \mathrm{SD}$ ), calculated on the basis of 32 controls, was from 0.735 to 1.151 , as presented in the scattergram. In the ulcerative colitis group 11 out of 20 patients tested at $25 \mu \mathrm{g}$ protein $/ \mathrm{ml}$ showed inhibition of leucocyte migration and in the Crohn's disease group four out of 20. This contrasted with the results seen in both control groups in which only one healthy subject showed a migration index below 0.735 (table I).

\begin{tabular}{llc}
\hline Group of Subjects & Total No. of Tests & $\begin{array}{l}\text { No. of Tests with } \\
M I<0.735^{1}\end{array}$ \\
\hline Healthy controls & 18 & 1 \\
Disease controls & 15 & - \\
Ulcerative colitis & 20 & 11 \\
Crohn's disease & 20 & 4 \\
\hline
\end{tabular}

Table I Leucocyte migration inhibition with Kunin antigen at $25 \mu \mathrm{g}$ protein/ml

${ }^{1}$ Lower limit of the normal range calculated as the mean of the controls \pm 2 standard deviations

In three patients with ulcerative colitis, migration inhibition was studied quantitatively. A graph (fig 3) shows a close relationship between the migration index and the concentration of Kunin antigen. As is shown in the graph the smallest concentrations of Kunin antigen which induced inhibition of leucocyte migration were between 1 and $2 \mu \mathrm{g}$ protein $/ \mathrm{ml}$ which is equivalent to 8 to $16 \mathrm{ng}$ of protein per hole.

Table II presents the full clinical data for patients with ulcerative colitis together with corresponding migration indices. There was no apparent correlation between sex, age, duration, or the extent of the disease and the response obtained with the antigen. Similarly, systemic steroids did not seem to influence the results of the test. It appears, however, that the occurrence of leucocyte migration inhibition might be to some extent dependent on clinical activity. Seven out of 11 patients who showed inhibition were in a very active phase of the disease, but only one out of nine patients who had migration indices within the normal range could be considered to have very active disease. Furthermore, in three patients with ulcerative colitis treated with steroids, migration indices, being low in an active phase, showed a tendency to rise after marked clinical improvement (table III). 


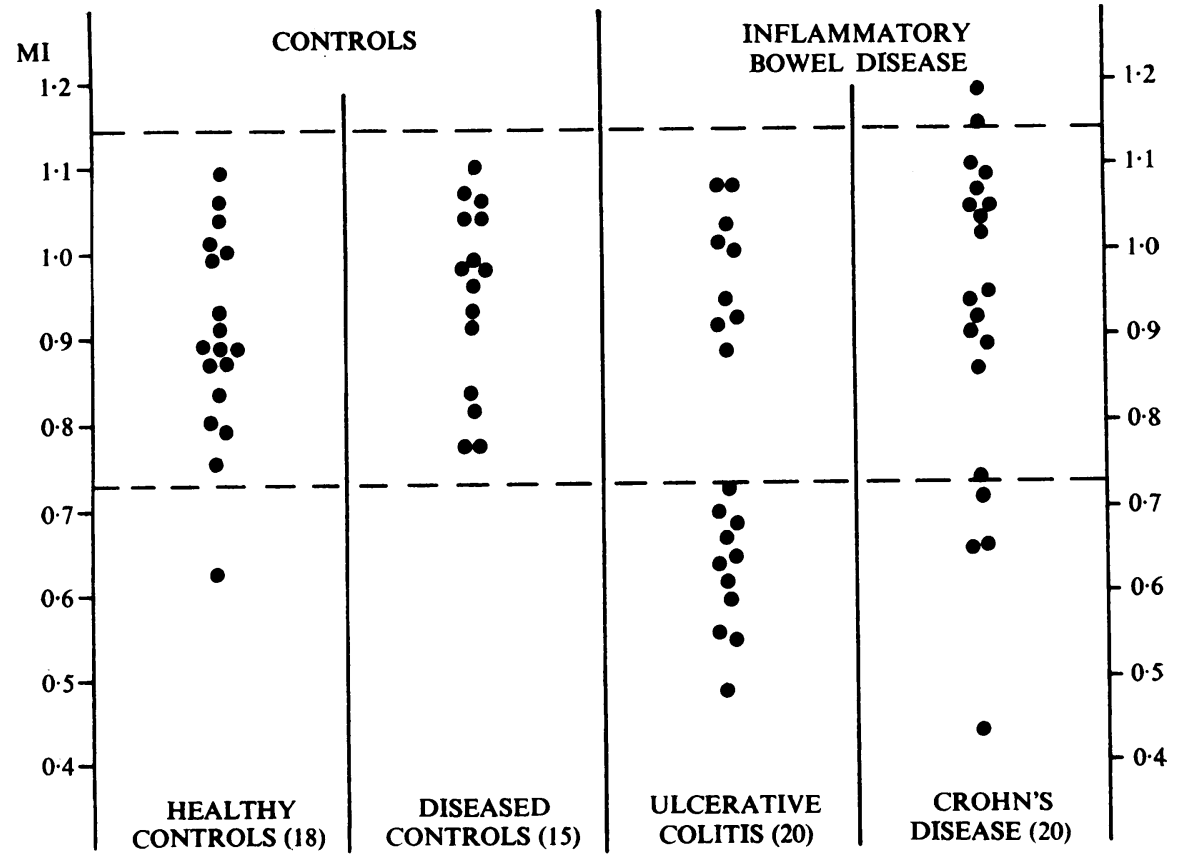

Fig 2

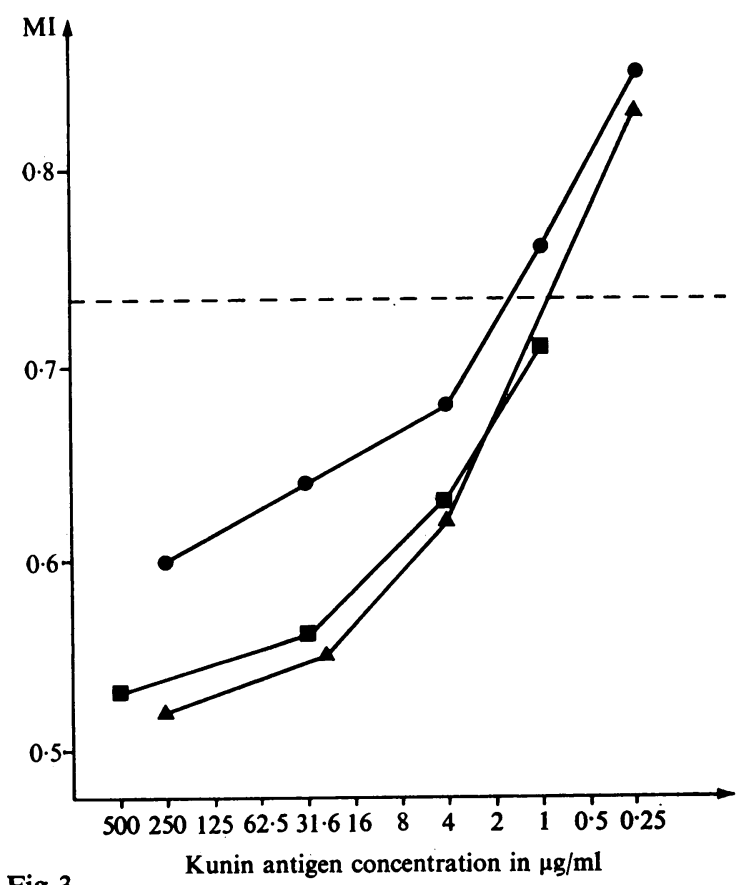

Fig 2 Scattergram of migration indices (MI) obtained with mixed peripheral leucocytes in the presence of Kunin antigen (25 $\mu \mathrm{g}$ protein/ml). Each point represents the mean of three determinations. The dotted lines indicate the normal range calculated from the mean of the controls \pm 2 standard deviations.

Fig 3 Relationship between migration index (MI) and the concentration of antigen in three different cases of ulcerative colitis. (Dotted line represents lower limit of the normal range.)

Fig 3

Kunin antigen concentration in $\mu \mathrm{g} / \mathrm{ml}$ 


\begin{tabular}{|c|c|c|c|c|c|c|c|}
\hline Patient No. & Sex & $\operatorname{Age}(y r)$ & Duration (yr) & Extent $t^{2}$ & Activity ${ }^{3}$ & $\begin{array}{l}\text { Systemic } \\
\text { Steroids }\end{array}$ & $\begin{array}{l}\text { Migration } \\
\text { Index }\end{array}$ \\
\hline $\begin{array}{r}1 \\
2 \\
3 \\
4 \\
5 \\
6 \\
7 \\
7 \\
8 \\
9 \\
10 \\
11 \\
12 \\
13 \\
14 \\
15 \\
16 \\
17 \\
18 \\
19 \\
20\end{array}$ & $\begin{array}{l}\mathbf{F} \\
\mathbf{F} \\
\mathbf{F} \\
\mathbf{F} \\
\mathbf{F} \\
\mathbf{F} \\
\mathbf{F} \\
\mathbf{M} \\
\mathbf{M} \\
\mathbf{M} \\
\mathbf{F} \\
\mathbf{M} \\
\mathbf{F} \\
\mathbf{M} \\
\mathbf{F} \\
\mathbf{F} \\
\mathbf{F} \\
\mathbf{M} \\
\mathbf{F} \\
\mathbf{M}\end{array}$ & $\begin{array}{l}25 \\
29 \\
61 \\
30 \\
35 \\
26 \\
66 \\
26 \\
57 \\
21 \\
35 \\
22 \\
40 \\
26 \\
27 \\
62 \\
48 \\
23 \\
72 \\
21\end{array}$ & $\begin{array}{l}9 \\
7 \\
5 \\
2 \mathrm{mth} \\
4 \\
10 \\
5 \\
3 \mathrm{wk} \\
15 \\
6 \mathrm{mth} \\
5 \\
7 \\
10 \\
2 \\
5 \\
4 \\
9 \\
2 \\
2.5 \\
1.5\end{array}$ & 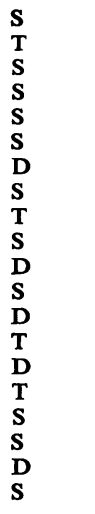 & $\begin{array}{l}++ \\
++ \\
++ \\
++ \\
+ \\
+ \\
++ \\
+ \\
++ \\
+ \\
++ \\
+ \\
+ \\
+ \\
+ \\
++ \\
+ \\
+ \\
+ \\
+\end{array}$ & $\begin{array}{l}\text { Yes } \\
\text { No } \\
\text { Yes } \\
\text { Yes } \\
\text { No } \\
\text { Yes } \\
\text { No } \\
\text { No } \\
\text { No } \\
\text { No } \\
\text { Yes } \\
\text { Yes } \\
\text { No } \\
\text { No } \\
\text { No } \\
\text { No } \\
\text { Yes } \\
\text { No } \\
\text { No } \\
\text { Yes }\end{array}$ & $\begin{array}{l}0.49 \\
0.55 \\
0.56 \\
0.60 \\
0.62 \\
0.64 \\
0.65 \\
0.67 \\
0.69 \\
0.70 \\
0.73 \\
0.89 \\
0.92 \\
0.93 \\
0.95 \\
1.01 \\
1.02 \\
1.04 \\
1.08 \\
1.08\end{array}$ \\
\hline
\end{tabular}

Table II Clinical data and migration indices in ulcerative colitis ${ }^{1}$

${ }^{1}$ The patients are arranged in order of increasing migration index.

'Extent of the disease radiologically:

$$
\left.\begin{array}{l}
\begin{array}{l}
D, \text { distal| } \\
\text { S, substantial } \\
T, \text { total }
\end{array}
\end{array}\right\} \text { involvement }
$$

\begin{tabular}{lll}
\hline Patient No. & Migration Index \\
\cline { 2 - 3 } & Before Treatment & After Clinical Improvement \\
\hline $1^{1}$ & 0.49 & 0.79 \\
$2^{2}$ & 0.56 & 0.67 \\
$3^{3}$ & 0.69 & 0.85 \\
\hline
\end{tabular}

Table III Migration indices before and after treatment

1,2,8Patients with ulcerative colitis treated with systemic steroids
'Disease activity assessed clinically:

$$
\left.\begin{array}{l}
0, \text { inactive } \\
+, \text { active } \\
++, \text { very active }
\end{array}\right\} \text { phase }
$$

Table IV presents full clinical data for patients with Crohn's disease with their corresponding migration indices. Again there was no correlation between sex, age, or duration of the disease and the response to Kunin antigen. An attempt to correlate the occurrence of leucocyte migration inhibition with the site of involvement of the gut is shown in table V. Although the number of subjects in each

\begin{tabular}{|c|c|c|c|c|c|c|c|}
\hline Patient No. & Sex & Age $(y r)$ & Duration (yr) & $\begin{array}{l}\text { Site of } \\
\text { Involvement }\end{array}$ & Activity $^{3}$ & $\begin{array}{l}\text { Systemic } \\
\text { Steroids }\end{array}$ & $\begin{array}{l}\text { Migration } \\
\text { Index }\end{array}$ \\
\hline $\begin{array}{r}1 \\
2 \\
3 \\
4 \\
5 \\
6 \\
7 \\
8 \\
9 \\
10 \\
11 \\
12 \\
13 \\
14 \\
15 \\
16 \\
17 \\
18 \\
19 \\
20\end{array}$ & $\begin{array}{l}\mathbf{F} \\
\mathbf{F} \\
\mathbf{M} \\
\mathbf{F} \\
\mathbf{F} \\
\mathbf{M} \\
\mathbf{F} \\
\mathbf{F} \\
\mathbf{F} \\
\mathbf{M} \\
\mathbf{F} \\
\mathbf{F} \\
\mathbf{M} \\
\mathbf{F} \\
\mathbf{F} \\
\mathbf{M} \\
\mathbf{M} \\
\mathbf{F} \\
\mathbf{F} \\
\mathbf{F}\end{array}$ & $\begin{array}{l}27 \\
18 \\
29 \\
43 \\
33 \\
45 \\
26 \\
20 \\
29 \\
24 \\
37 \\
53 \\
25 \\
28 \\
33 \\
67 \\
62 \\
39 \\
43 \\
32\end{array}$ & $\begin{array}{c}3 \\
1 \\
6 \\
23 \\
10 \\
14 \\
13 \\
4 \\
1 \cdot 5 \\
1 \cdot 5 \\
12 \\
4 \\
6 \\
9 \\
5 \\
3 \\
7 \\
2 \\
12 \\
8\end{array}$ & $\begin{array}{l}\mathbf{i}+\mathbf{c} \\
\mathbf{c} \\
\mathbf{c} \\
\mathrm{c} \\
\mathbf{i} \\
\mathbf{i}+\mathbf{c} \\
\mathbf{i}+\mathbf{c} \\
\mathbf{i}+\mathbf{c} \\
\mathbf{i}+\mathbf{c} \\
\mathbf{i}+\mathbf{c} \\
\mathbf{i} \\
\mathbf{c} \\
\mathbf{c} \\
\mathbf{i}+\mathbf{c} \\
\mathbf{i}+\mathbf{c} \\
\mathbf{i}+\mathbf{c} \\
\mathbf{c} \\
\mathbf{i} \\
\mathbf{i}+\mathbf{c} \\
\mathbf{i}\end{array}$ & $\begin{array}{l}+ \\
++ \\
0 \\
+ \\
++ \\
+ \\
+ \\
++ \\
0 \\
++ \\
+ \\
0 \\
+ \\
+ \\
+ \\
+ \\
++ \\
+ \\
0 \\
+\end{array}$ & $\begin{array}{l}\text { Yes } \\
\text { Yes } \\
\text { Yes } \\
\text { Yes } \\
\text { No } \\
\text { Yes } \\
\text { No } \\
\text { No } \\
\text { Yes } \\
\text { No } \\
\text { Yes } \\
\text { Yes } \\
\text { Yes } \\
\text { Yes } \\
\text { No } \\
\text { No } \\
\text { No } \\
\text { Yes } \\
\text { Yes } \\
\text { Yes }\end{array}$ & $\begin{array}{l}0.44 \\
0.66 \\
0.66 \\
0.72 \\
0.74 \\
0.87 \\
0.90 \\
0.91 \\
0.93 \\
0.95 \\
0.96 \\
1.03 \\
1.05 \\
1.06 \\
1.06 \\
1.08 \\
1.10 \\
1.11 \\
1.16 \\
1.20\end{array}$ \\
\hline
\end{tabular}
group is too small to draw definite conclusions it is

Table IV Clinical data and migration indices in Crohn's disease

${ }^{1}$ The patients are arranged in order of increasing migration index.

'Site of involvement of the gut:

i, small bowel involved

'Disease activity assessed clinically:

c, colon involved

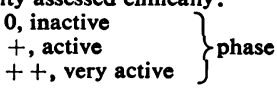




\begin{tabular}{lcl}
\hline Site of Involvement & No. of All Patients & $\begin{array}{l}\text { No. of Patients with } \\
M I<0.735^{1}\end{array}$ \\
\hline Small bowel & 4 & - \\
Small and large bowel 10 & 1 \\
Large bowel & 6 & 3 \\
\hline
\end{tabular}

Table V Leucocyte migration inhibition in Crohn's disease

'Lower limit of the normal range

worth noting that no patient with disease confined to the small bowel showed inhibition. No correlation was observed between the occurrence of Kunin antigen-induced leucocyte migration inhibition and clinical activity of Crohn's disease. However, in one patient with colonic involvement, the migration index being low preoperatively returned to normal eight days after colectomy.

An extract from germ-free rat faeces and Kveim suspension did not induce inhibition of leucocyte migration either in patients with ulcerative colitis or in those with Crohn's disease. The only exception was one patient with Crohn's disease in whom the migration index with Kveim suspension was 0.76 (table VI). In patients with inflammatory bowel diseases, germ-free rat faeces extract seemed, if anything, to enhance slightly leucocyte migration, but the meaning of this finding is not clear. Leucocytes from two patients with ulcerative colitis were tested at concentrations as high as $2500 \mu \mathrm{g}$ protein/ $\mathrm{ml}$ without inhibition (migration indices 0.91 and 0.92). of migration inhibition appeared to be related to the activity of ulcerative colitis (table II) and in three patients who were tested in the active phase of the disease and again after marked clinical improvement, migration indices returned to normal or almost normal (table III). The decreased inhibition was unlikely to have been a non-specific effect of systemic steroids since other patients with clinically active disease showed inhibition in spite of steroid therapy. The reversal of the migration index in one patient with Crohn's disease of the large bowel treated surgically is comparable to the loss of cytotoxicity of lymphocytes to colonic epithelial cells after colectomy, as described by Shorter, Cardoza, Spencer, and Huizenga (1969).

Leucocyte migration inhibition with Kunin antigen was almost three times as frequent in patients with ulcerative colitis as in those with Crohn's disease although the degree of inhibition was the same in both groups. Using a capillary tube method, Bendixen has shown that extracts from colonic mucosa inhibited migration of peripheral leucocytes in a majority of patients with ulcerative colitis but only rarely in patients with Crohn's disease. He concluded that there was a biological difference between the two diseases (Bendixen, 1969). Although evidence suggests that Kunin antigen is related to colonic antigen(s) (Perlmann et al, 1965; Lagercrantz et al, 1968), it is probable that they do not share all their antigenic determinants, and this could explain the differences between Bendixen's results and our own. The cytotoxicity of lymphocytes

\begin{tabular}{|c|c|c|}
\hline \multirow[t]{2}{*}{ Group of Subjects } & \multicolumn{2}{|l|}{ Migration Index Range with } \\
\hline & $\begin{array}{l}\text { Germ-free Rat Faeces Extract at } \\
500 \mathrm{\mu g} \text { protein } / \mathrm{ml}\end{array}$ & Kveim Suspension" \\
\hline $\begin{array}{l}\text { Healthy controls } \\
\text { Disease controls } \\
\text { Ulcerative colitis } \\
\text { Crohn's disease }\end{array}$ & $\begin{array}{l}0 \cdot 83-1 \cdot 15 \quad(6)^{1} \\
-0 \cdot 91-1 \cdot 25(13) \\
1 \cdot 00-1 \cdot 13\end{array}$ & $\begin{array}{l}0.92-1.06 \quad(6) \\
0.83-1.09(13) \\
0.82-1.05(11) \\
0.76^{8}-1 \cdot 18(14)\end{array}$ \\
\hline
\end{tabular}

Table VI Leucocyte migration index in four groups studied

${ }^{1}$ Number of subjects tested in brackets

${ }^{2}$ This was applied without any preparation being added to the same volumes of the leucocyte suspension

${ }^{3}$ Only one patient had MI $<0.8$

\section{Discussion}

Our results suggest that a state of cellular immunity to the common antigen of Kunin, as judged by inhibition of leucocyte migration, exists in a proportion of patients with ulcerative colitis and Crohn's disease. Bull and Ignaczak (1973) have recently reported similar results obtained with the same antigen in a macrophage migration inhibition test.

It is interesting that the occurrence and the degree for colonic epithelial cells in vitro, which may be considered to involve cellular immune mechanisms, is the same in the two conditions (Watson, Quigley, and Bolt, 1966; Shorter et al, 1969; Shorter et al, 1971).

We were unable to show inhibition of peripheral leucocyte migration using extracts of germ-free rat faeces, although using a similar antigen Bendixen obtained inhibition in the same patients with ulcerative colitis in whom cellular reactivity to intestinal 
extracts was observed (Bendixen, 1971). In another study Dykes has found that inhibition of leucocyte migration in the presence of human faecal extracts or small bowel contents occurred in Crohn's disease but not in ulcerative colitis (Dykes, 1970). We were also unable to show inhibition with Kveim suspension from sarcoid spleen $\mathrm{K} 19$, unlike Willoughby and Mitchell who demonstrated inhibition in 12 out of 18 patients with Crohn's disease but in no case of ulcerative colitis using the same antigen (Willoughby and Mitchell, 1971). Similar results to those of the latter group have been reported by Brostoff and Walker (1971) with Kveim suspension deriving from sarcoid spleen $\mathrm{K} 12$. The only differences between these studies and our own have been the techniques used. In the agarose plate technique minute amounts of antigen are used and it is therefore probable that more pure antigens are required than in the capillary tube method. It is possible that extracts from germ-free rat faeces containing $6 \%$ of protein and an unprepared, flocculant Kveim suspension are both too crude test materials for the agarose plate method. None of them, although used in high concentrations, yielded positive results in this method. On the other hand, purified Kunin antigen induced inhibition of migration in doses as small as nanograms.

The differential diagnosis between ulcerative colitis and colonic Crohn's disease, usually made on nosological criteria, may prove very difficult in some cases. In such cases a relatively simple immunological test would be of great value. In this context it is especially interesting that in most of our patients with Crohn's disease who showed leucocyte migration inhibition with Kunin antigen, only the large bowel was involved, and therefore our test has not been useful in distinguishing the two conditions.

We, like Clausen (1971), have found the agarose plate technique to be quicker and more simple to use than the capillary tube method. The areas of migration are more regular and therefore more easily and more accurately measured, and the results are highly reproducible. Only small amounts of antigen are required although it is probable that they should be more purified.

Our results with Kunin antigen support the hypothesis that cell-mediated immune mechanisms may play a role in the pathogenesis of inflammatory bowel disease. Bacterial antigens present in large amounts in the gut and closely related to colonic antigens may invoke an immune response which is directed against the intestinal mucosa itself. This hypothesis requires further immunological studies employing different antigens and techniques.
We should like to thank Dr S. Kaluzewski of the Department of Bacteriology of the State Institute of Hygiene, Warsaw, Dr D. N. Mitchell of the MRC Tuberculosis and Chest Diseases Unit, Brompton Hospital, Dr C. M. Patricia Bradstreet of the Standards Laboratory for Serological Reagents, Colindale, and Professor P. Perlmann of the Wenner-Gren Institute, Stockholm, for the antigens we have used; Dr D. C. Dumonde and R. N. Maini of the Kennedy Institute, for their advice and encouragement and Dr J. E. Lennard-Jones for his support and for giving us access to his patients. One of us (W.B.) was in receipt of a WHO fellowship.

\section{References}

Bendixen, G. (1969). Cellular hypersensitivity to components of intestinal mucosa in ulcerative colitis and Crohn's disease. Gut, $10,631-636$.

Bendixen, G. (1971). Cellular hypersensitivity in ulcerative colitis and Crohn's disease. Schweiz. med. Wschr., 101, 698-701.

Brostoff, J., and Walker, J. G. (1971). Leucocyte migration inhibition with Kveim antigen in Crohn's disease. Clin. exp. Immunol., 9, 707-711.

Bull, D. M., and Ignaczak, T. F. (1973). Enterobacterial common antigen-induced lymphocyte reactivity in inflammatory bowel disease. Gastroenterology, 64, 43-50.

Clausen, J. E. (1971). Tuberculin-induced migration inhibition of human peripheral leucocytes in agarose medium. Acta allerg. $\left(K b h_{0}\right)$, 26, 56-80.

Dykes, P. W. (1970). Delayed hypersensitivity in Crohn's disease. Proc. roy. Soc. Med., 63, 906-908.

Hammarström, S., Lagercrantz, R., Perlmann, P., and Gustafsson, B. E. (1965). Immunological studies in ulcerative colitis. II. 'Colon' antigen and human blood group A- and H-like antigens in germ free rats. J. exp. Med., 122, 1075-1086.

Kraft, S. C., Kirsner, J. B. (1971). Immunological apparatus of the gut and inflammatory bowel disease. Gastroenterology, 60, 922-951.

Kunin, C. M. (1963). Separation, characterization and biological significance of a common antigen in Enterobacteriaceae. J. exp. Med., 118, 565-586.

Lagercrantz, R., Hammarström, S., Perlmann, P., and Gustafsson, B. E. (1968). Immunological studies in ulcerative colitis. IV. Origin of autoantibodies. J. exp. Med., 128, 1339-1352.

Lagercrantz, R., Perlmann, P., Hammarström, S. (1971). Immunological studies in ulcerative colitis. V. Family studies. Gastroenterology, 60, 381-389.

Perlmann, P., Hammarström, S., Lagercrantz, R., and Gustafsson, B. E. (1965). Antigen from colon of germfree rats and antibodies in human ulcerative colitis. Ann. N.Y. Acad. Sci., 124, 377-394.

Shorter, R. G., Cardoza, M., Spencer, R. J., and Huizenga, K. A. (1969). Further studies of in vitro cytotoxicity of lymphocytes from patients with ulcerative and granulomatous colitis for allogeneic colonic epithelial cells, including the effects of colectomy. Gastroenterology, 56, 304-309.

Shorter, R. G., Huizenga, K. A., Spencer, R. J., Aas, J., and Guy, S. K. (1971). Inflammatory bowel disease: cytophilic antibody and the cytotoxicity of lymphocytes for colonic cells in vitro. Amer J. dig. Dis., 16, 673-680.

Suzuki, T., Gorzynski, E. A., Neter, E. (1964). Separation by ethanol of common and somatic antigens of Enterobacteriaceae. $J$. Bact., 88, 1240-1243.

Thayer, W. R. J., Jr., Brown, M., Sangree, M. H., Katz, J., and Hersh, T. (1969). Escherichia coli 0:14 and colon hemagglutinating antibodies in inflammatory bowel disease. Gastroenterology, 57, 311-318.

Watson, D. W., Quigley, A., and Bolt, R. J. (1966). Effect of lymphocytes from patients with ulcerative colitis on human adult colon epithelial cells. Gastroenterology, 51, 985-993.

Willoughby, J. M. T., and Mitchell, D. N. (1971). In-vitro inhibition of leucocyte migration in Crohn's disease by sarcoid spleen suspension. Brit. med. J., 3, 155-157. 